\title{
Application of GPS radio occultation to the assessment of temperature profile retrievals from microwave and infrared sounders
}

\author{
M. Feltz ${ }^{1,3}$, R. Knuteson ${ }^{2}$, S. Ackerman ${ }^{3}$, and H. Revercomb ${ }^{2}$ \\ ${ }^{1}$ Department of Atmospheric and Oceanic Sciences, University of Wisconsin - Madison, Madison, Wisconsin, USA \\ ${ }^{2}$ Space Science and Engineering Center, University of Wisconsin - Madison, Madison, Wisconsin, USA \\ ${ }^{3}$ Cooperative Institute for Meteorological Satellite Studies, University of Wisconsin - Madison, Madison, Wisconsin, USA
}

Correspondence to: M. Feltz (michelle.feltz@ssec.wisc.edu)

Received: 7 March 2014 - Published in Atmos. Meas. Tech. Discuss.: 22 May 2014

Revised: 21 August 2014 - Accepted: 23 September 2014 - Published: 12 November 2014

\begin{abstract}
Comparisons of satellite temperature profile products from GPS radio occultation (RO) and hyperspectral infrared (IR)/microwave (MW) sounders are made using a previously developed matchup technique. The profile matchup technique matches GPS RO and IR/MW sounder profiles temporally, within $1 \mathrm{~h}$, and spatially, taking into account the unique RO profile geometry and theoretical spatial resolution by calculating a ray-path averaged sounder profile. The comparisons use the GPS RO dry temperature product. Sounder minus GPS RO differences are computed and used to calculate bias and rms profile statistics, which are created for global and $30^{\circ}$ latitude zones for selected time periods. These statistics are created from various combinations of temperature profile data from the Constellation Observing System for Meteorology, Ionosphere \& Climate (COSMIC) network, Global Navigation Satellite System Receiver for Atmospheric Sounding (GRAS) instrument, and the Atmospheric Infrared Sounder (AIRS)/Advanced Microwave Sounding Unit (AMSU), Infrared Atmospheric Sounding Interferometer (IASI)/AMSU, and Crosstrack Infrared Sounder (CrIS)/Advanced Technology Microwave Sounder (ATMS) sounding systems. By overlaying combinations of these matchup statistics for similar time and space domains, comparisons of different sounders' products, sounder product versions, and GPS RO products can be made. The COSMIC GPS RO network has the spatial coverage, time continuity, and stability to provide a common reference for comparison of the sounder profile products. The results of this study demonstrate that GPS RO has potential to act as a common temperature reference and can help fa-
\end{abstract}

cilitate inter-comparison of sounding retrieval methods and also highlight differences among sensor product versions.

\section{Introduction}

Historically, in situ measurements from the World Meteorological Organization (WMO) global radiosonde network have been the reference for characterization of atmospheric temperature profiles derived from satellite sounders (Fetzer et al., 2003; Divakarla et al., 2006; Thorne et al., 2011; Seidel et al., 2011; Reale et al., 2012). The sensors on such radiosondes have calibrations provided by the sensor vendors, which have been shown to contain errors (Turner et al., 2003). Due to the wide range of accuracies among radiosonde systems, it is challenging to use the existing WMO operational radiosonde network as a common reference (Seidel et al., 2009). In current practice, it is popular to use numerical weather prediction (NWP) forecast models that assimilate WMO radiosondes twice a day as a primary way to validate sounder satellite products, because even a single model time step can provide thousands of global matchup cases with the satellite products (Fetzer et al., 2003; Divakarla et al., 2014). However, there is a potential for circular calibration traceability paths for operational satellite product data sets when using this method due to the fact that cloudfree radiances are assimilated into NWP models, while at the same time satellite retrieval algorithms are tuned to agree with global mean NWP forecast assimilation data (McNally 
et al., 2006; Susskind et al., 2006). This motivates the need for sounder validation data that have independent calibration traceability to the International System of Units (SI) (Thompson and Taylor, 2008). One such candidate is a research grade radiosonde like the Vaisala RS92 launched at selected satellite overpass times; however, it is not economical to provide these data for more than a campaign basis from a limited number of locations (Tobin et al., 2006; Nalli et al., 2013).

Several characteristics of Global Positioning System (GPS) radio occultation (RO) serve as reasons for why RO data can be useful for sounder comparison purposes (Yunck et al., 2009). RO's traceability to international standards has made it a candidate for long-term climate records (Mannucci et al., 2006; Leroy et al., 2006). Because RO measurements are based on a common time standard, GPS RO observations from different RO instruments and networks should have similar observation accuracies (Kursinski et al., 1997; Anthes et al., 2008). However, due to the various processing schemes offered by different data centers, there is a structural uncertainty associated with GPS RO derived products (Ho et al., 2012; Steiner et al., 2013). GPS RO also provides very stable observations due to the high accuracy and reliability of the RO instrument clocks used to monitor the radio occultations (Leroy et al., 2006; Foelsche et al., 2008; Steiner et al., 2011). GPS RO offers global sampling that is not biased to have more frequent observations over land, unlike the WMO radiosonde network. GPS RO gives observations for given geographic locations that are also not biased to occur for only certain times of the day, such as sounders that operate from satellites with sun-synchronous orbits at fixed local times or WMO radiosondes launched only at 00:00 and 12:00 UTC.

Beyond simply providing a useful common reference for the comparison of infrared (IR)/microwave (MW) sounder products, GPS RO may also offer valuable insight into the error characteristics of sounder retrievals. Previous studies have suggested that GPS RO could be used to assess sounder product accuracies and brightness temperature observations (Yunck et al., 2009; Ho et al., 2009; von Engeln et al., 2010; Weng et al., 2013; Feltz et al., 2014, 2013; Zou et al., 2014). The active GPS RO measurements have higher vertical resolution than the passive near nadir sounders (Kursinski et al., 1997; Staten and Reichler, 2009; Yunck et al., 2009). For the upper troposphere/lower stratosphere (UTLS) region, GPS RO temperature profiles may also have a smaller absolute uncertainty than current IR/MW sounder products. Example sounder rms error requirements for temperature profiles are on the order of $1.5 \mathrm{~K}$ or better for $3 \mathrm{~km}$ layers between 300 and $30 \mathrm{hPa}$, whereas GPS RO precision has been estimated by Staten and Reichler (2009) to be less than $0.5 \mathrm{~K}$ in the same region. GPS RO dry temperature products suffer from uncertainty in the upper stratosphere due to errors in the ionospheric corrections and in the middle to lower troposphere where they are significantly lower than actual temperatures due to the presence of water vapor (Kursinski et al., 1997; Ware et al., 1996; Hajj et al., 2002).

The objective of this paper is to demonstrate the application of GPS radio occultation to the assessment of temperature profile products from the current operational data sets of IR/MW sounders. Examples of (1) the value of high absolute accuracy GPS RO for use in sounder product version updates, (2) the use of the GPS RO network as a common comparison reference for sounder products from different sensor platforms, and (3) differences between two current GPS RO networks using sounder data as a common reference will be illustrated. Data sources will be described, the comparison methodology outlined, and results from several comparison cases shown before concluding.

\section{Data}

\subsection{GPS RO data}

For this study, GPS RO data from the US/Taiwan Constellation Observing System for Meteorology, Ionosphere \& Climate (COSMIC) network and Global Navigation Satellite System Receiver for Atmospheric Sounding (GRAS) instruments are used. COSMIC, also known as Taiwan's Formosa Satellite Mission \#3 (FORMOSAT-3), is a mission consisting of six radio receivers in circular $72^{\circ}$ inclination orbits (Anthes et al., 2008). The COSMIC network produces around 1000-2000 profiles per day with a relatively sparser sampling of the tropics than other latitudes. In contrast, the GRAS instruments are hosted onboard the Metop series of operational weather satellites in a sun-synchronous late morning orbit (Klaes et al., 2007). This will be an important distinction to note for considering matchup data set sample sizes in statistical comparisons.

In order to use a consistent processing approach, all GPS RO data in this study are obtained from the University Corporation for Atmospheric Research (UCAR) COSMIC Data Analysis and Archive Center (CDAAC). The post-processed dry temperature products, identified by the label "atmPrf", are used. Specifically, the COSMIC data used are version 2010.2640 and the Metop-A GRAS data used are version 2011.2980. Known differences in these product versions that are likely to have the biggest impact on the results shown are located in the excess phase processing where the COSMIC data are processed in a single-difference mode and Metop-A data are processed in a zero-difference mode due to the high stability of the GRAS clock. Differences in the inversion processing between the two versions (where excess phase data are used to compute bending angle and subsequently refractivity profiles) affect the open-loop data processing that only impacts the lower troposphere, which is not considered in this study (UCAR, D. Hunt, personal communication, 2013). 
Table 1. Bottom bounding COSMIC mean sea level altitudes $(\mathrm{km})$ and corresponding degraded layer widths (km) for selected latitude zones for the May 2012 COSMIC/AIRS matchup cases. Degrading was applied between set pressure levels of which the bottom bounding values are seen in the first column.

\begin{tabular}{|c|c|c|c|c|c|c|c|c|c|c|c|c|}
\hline \multirow[b]{2}{*}{$\begin{array}{l}\text { Pressure } \\
(\mathrm{hPa})\end{array}$} & \multicolumn{2}{|c|}{ Global } & \multicolumn{2}{|c|}{$90-60^{\circ} \mathrm{N}$} & \multicolumn{2}{|c|}{$60-30^{\circ} \mathrm{N}$} & \multicolumn{2}{|c|}{$30^{\circ} \mathrm{N}-30^{\circ} \mathrm{S}$} & \multicolumn{2}{|c|}{$30-60^{\circ} \mathrm{S}$} & \multicolumn{2}{|c|}{$60-90^{\circ} \mathrm{S}$} \\
\hline & $\begin{array}{r}\text { Altitude } \\
(\mathrm{km})\end{array}$ & $\begin{array}{r}\text { Width } \\
(\mathrm{km})\end{array}$ & $\begin{array}{r}\text { Altitude } \\
(\mathrm{km})\end{array}$ & $\begin{array}{r}\text { Width } \\
(\mathrm{km})\end{array}$ & $\begin{array}{r}\text { Altitude } \\
(\mathrm{km})\end{array}$ & $\begin{array}{r}\text { Width } \\
(\mathrm{km})\end{array}$ & $\begin{array}{r}\text { Altitude } \\
(\mathrm{km})\end{array}$ & $\begin{array}{r}\text { Width } \\
(\mathrm{km})\end{array}$ & $\begin{array}{r}\text { Altitude } \\
(\mathrm{km})\end{array}$ & $\begin{array}{r}\text { Width } \\
(\mathrm{km})\end{array}$ & $\begin{array}{r}\text { Altitude } \\
(\mathrm{km})\end{array}$ & $\begin{array}{r}\text { Width } \\
(\mathrm{km})\end{array}$ \\
\hline 2.1526 & 41.66 & $\mathrm{NaN}$ & 42.738 & $\mathrm{NaN}$ & 42.558 & $\mathrm{NaN}$ & 42.308 & $\mathrm{NaN}$ & 40.696 & $\mathrm{NaN}$ & 38.285 & $\mathrm{NaN}$ \\
\hline 3.3398 & 38.438 & 3.2218 & 39.356 & 3.3826 & 39.196 & 3.3614 & 39.007 & 3.3015 & 37.683 & 3.0126 & 35.424 & 2.861 \\
\hline 4.9204 & 35.692 & 2.7463 & 36.48 & 2.8752 & 36.333 & 2.8632 & 36.187 & 2.82 & 35.103 & 2.5803 & 33 & 2.424 \\
\hline 5.8776 & 34.461 & 1.2309 & 35.195 & 1.2851 & 35.053 & 1.2801 & 34.922 & 1.265 & 33.94 & 1.1634 & 31.916 & 1.084 \\
\hline 6.9567 & 33.309 & 1.152 & 33.994 & 1.2008 & 33.857 & 1.1955 & 33.737 & 1.1843 & 32.846 & 1.0936 & 30.902 & 1.0141 \\
\hline 9.5119 & 31.204 & 2.105 & 31.806 & 2.1882 & 31.681 & 2.177 & 31.573 & 2.1642 & 30.835 & 2.0111 & 29.046 & 1.8559 \\
\hline 11.004 & 30.236 & 0.96805 & 30.803 & 1.0035 & 30.683 & 0.99774 & 30.578 & 0.99545 & 29.905 & 0.92994 & 28.19 & 0.85603 \\
\hline 16.432 & 27.604 & 2.6323 & 28.082 & 2.7204 & 27.982 & 2.701 & 27.872 & 2.7057 & 27.359 & 2.5461 & 25.852 & 2.3385 \\
\hline 20.922 & 26.037 & 1.567 & 26.465 & 1.6171 & 26.381 & 1.6003 & 26.268 & 1.6037 & 25.832 & 1.5275 & 24.448 & 1.4043 \\
\hline 32.274 & 23.257 & 2.78 & 23.59 & 2.8756 & 23.552 & 2.829 & 23.454 & 2.8143 & 23.099 & 2.7321 & 21.923 & 2.5242 \\
\hline 43.1 & 21.421 & 1.8357 & 21.68 & 1.9095 & 21.689 & 1.8637 & 21.626 & 1.828 & 21.283 & 1.8165 & 20.227 & 1.6966 \\
\hline 60.989 & 19.237 & 2.1841 & 19.392 & 2.2888 & 19.473 & 2.2162 & 19.498 & 2.1281 & 19.106 & 2.1765 & 18.168 & 2.0586 \\
\hline 83.231 & 17.3 & 1.937 & 17.343 & 2.0487 & 17.501 & 1.9712 & 17.671 & 1.8273 & 17.158 & 1.9482 & 16.298 & 1.8699 \\
\hline 103.02 & 15.973 & 1.3265 & 15.937 & 1.4056 & 16.148 & 1.3534 & 16.438 & 1.2324 & 15.819 & 1.3391 & 15 & 1.2983 \\
\hline 125.65 & 14.73 & 1.2434 & 14.626 & 1.3116 & 14.881 & 1.2674 & 15.275 & 1.1627 & 14.567 & 1.2519 & 13.779 & 1.2207 \\
\hline 142.38 & 13.94 & 0.78961 & 13.797 & 0.82834 & 14.078 & 0.80251 & 14.527 & 0.74822 & 13.776 & 0.79174 & 13.005 & 0.77434 \\
\hline 160.5 & 13.18 & 0.76082 & 13.003 & 0.79431 & 13.308 & 0.77033 & 13.797 & 0.73069 & 13.016 & 0.75967 & 12.26 & 0.74494 \\
\hline 190.32 & 12.09 & 1.09 & 11.872 & 1.1315 & 12.211 & 1.0966 & 12.728 & 1.0685 & 11.936 & 1.0801 & 11.197 & 1.0639 \\
\hline 223.44 & 11.057 & 1.0326 & 10.81 & 1.0613 & 11.18 & 1.0308 & 11.688 & 1.0405 & 10.92 & 1.0161 & 10.197 & 0.9996 \\
\hline 272.92 & 9.7531 & 1.3032 & 9.4977 & 1.3126 & 9.8797 & 1.2998 & 10.34 & 1.3482 & 9.6379 & 1.2818 & 8.9561 & 1.241 \\
\hline 314.14 & 8.8173 & 0.93506 & 8.576 & 0.92177 & 8.943 & 0.93669 & 9.3571 & 0.98231 & 8.7147 & 0.92312 & 8.075 & 0.88108 \\
\hline 343.62 & 8.2095 & 0.60747 & 7.9826 & 0.59339 & 8.3328 & 0.61025 & 8.7164 & 0.64073 & 8.1136 & 0.60116 & 7.5041 & 0.57087 \\
\hline 407.47 & 7.0277 & 1.1814 & 6.8323 & 1.1503 & 7.1435 & 1.1886 & 7.4708 & 1.2454 & 6.9426 & 1.1714 & 6.3937 & 1.1104 \\
\hline 477.96 & 5.8897 & 1.1376 & 5.7237 & 1.1089 & 5.9967 & 1.1457 & 6.2773 & 1.1936 & 5.8123 & 1.1303 & 5.3211 & 1.0726 \\
\hline 535.23 & 5.0653 & 0.82372 & 4.9187 & 0.80514 & 5.1653 & 0.8299 & 5.4191 & 0.8583 & 4.9916 & 0.82068 & 4.5412 & 0.7799 \\
\hline 617.51 & 4.0124 & 1.0575 & 3.8817 & 1.0371 & 4.0994 & 1.0645 & 4.3277 & 1.0915 & 3.9346 & 1.0568 & 3.5411 & 1.009 \\
\hline 683.67 & 3.2577 & 0.76155 & 3.133 & 0.74876 & 3.3338 & 0.76464 & 3.5486 & 0.77844 & 3.1704 & 0.76385 & 2.817 & 0.73451 \\
\hline 777.79 & 2.2904 & 0.9712 & 2.1712 & 0.95857 & 2.3561 & 0.97373 & 2.5656 & 0.98245 & 2.1932 & 0.97704 & 1.8776 & 0.94731 \\
\hline 878.62 & 1.3738 & 0.91487 & 1.2538 & 0.91172 & 1.4341 & 0.91983 & 1.6584 & 0.911 & 1.2676 & 0.91982 & 0.97885 & 0.90529 \\
\hline 1100 & 0.26848 & 1.5807 & $\mathrm{NaN}$ & $\mathrm{NaN}$ & 0.18528 & 1.6215 & 0.2846 & 1.5744 & 0.080176 & 1.622 & $\mathrm{NaN}$ & $\mathrm{NaN}$ \\
\hline
\end{tabular}

Also used from the CDAAC is the ERA-40 Interim reanalysis product, labeled "eraPrf", which are profiles created by collocation of the ERA-Interim model with the GPS RO occultation profiles. Specifically, this study uses the ERA data that correspond with the COSMIC mission.

\subsection{IR/MW sounder data}

The temperature profile measurements derived from NASA's Atmospheric Infrared Sounder (AIRS)/Advanced Microwave Sounding Unit (AMSU) sensors on the Earth Observing System Aqua satellite are obtained from the Goddard Earth Sciences Data and Information Services Center. The Level-2 (L2) version 5.2 (v5.2) and version 6.0 (v6.0) Support Products are used, which provide temperature measurements at 101 vertical pressure levels (Susskind et al., 2011). Quality control consists of using the AIRS L2 quality flags (Susskind et al., 2011). In particular, this study uses a quality flag, labeled "Pbest", which determines how deep into the atmosphere the satellite retrieval is considered to be valid.

The Infrared Atmospheric Sounding Interferometer (IASI) sounder data produced by NOAA using a customized version of the AIRS science team algorithm (v5.2) are obtained from the NOAA Comprehensive Large Array-data Stewardship System (CLASS) website (www.class.noaa.gov). The data used, only available from the Metop-A satellite for the studied time period, are the L2 product named "Infrared Atmospheric Sounding Interferometer Granule Data (IASI)". Quality control is applied using the quality flag provided in the L2 data files by excluding profiles marked with nonzero values for the flag. EUMETSAT-processed L2 IASI data are not used in this study due to the fact that an expected major version upgrade was not available at the time of the study.

Cross-Track Infrared and Microwave Sounder Suite (CrIMSS) data from the Suomi National Polar-orbiting Partnership (NPP) satellite are also obtained from NOAA CLASS. Specifically, the 42 temperature layer Atmospheric Vertical Temperature Profile product is used 

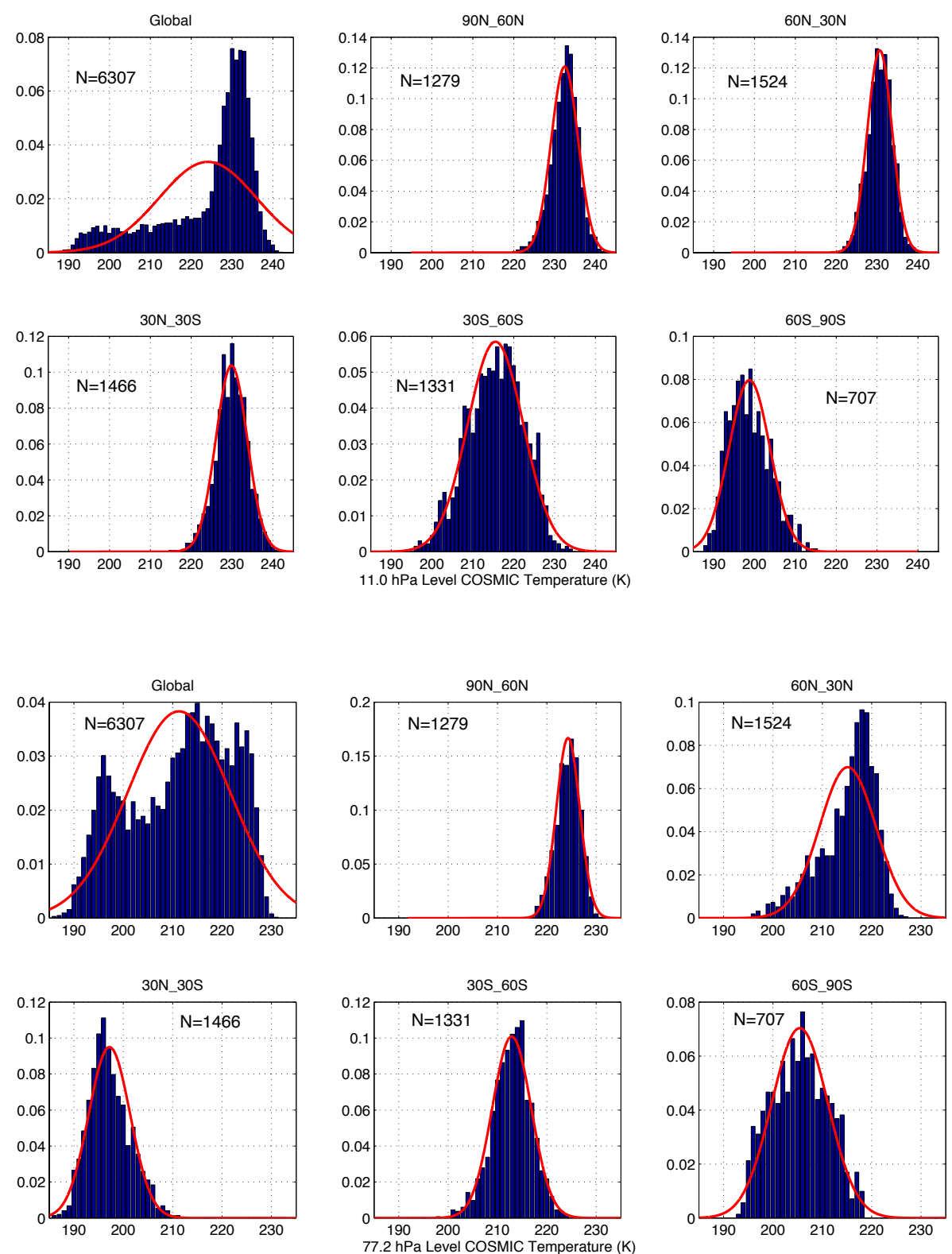

Figure 1. Probability density functions of COSMIC dry temperature in the stratosphere at $11 \mathrm{hPa}$ (upper six panels) and near the tropical tropopause at $77 \mathrm{hPa}$ (lower six panels) in one global and five latitude zones (blue), with overlaid normal distributions calculated from the mean and standard deviation (red). Data are extracted from the AIRS/COSMIC matchup data set for May 2012, with the number of matchup samples, $N$, for the corresponding latitude zone shown within each panel.

(JPSS Configuration Management Office, 2012). CrIMSS data for the example time period May 2012 that are used in this study are version Mx5.3 and are from the time when the product was still in provisional status prior to major subsequent upgrades (Divakarla et al., 2014). Evaluation of the NOAA products derived from the Crosstrack Infrared Sounder (CrIS)/Advanced Technology Microwave Sounder (ATMS) on the Suomi NPP satellite is ongoing and GPS RO is being used in the product calibration/validation (Nalli et al., 2013). Quality control is applied using the overall retrieval quality flag - non-converged retrievals are not included in the analysis. Details of the CrIMSS product algorithm can be found in Divakarla et al. (2014).

\section{Methodology}

To obtain the various GPS RO and sounder temperature profile matchup data sets used in this study, the matchup methodology described in Feltz et al. (2014) is employed. This matchup methodology has a 1-hour matchup time 
criterion and calculates a "ray-path" sounder profile that accounts for the GPS RO profile geometry and theoretical spatial resolution. After the spatially and temporally matched temperature profiles are found, all profiles are interpolated to be on the 101 pressure levels of the AIRS sounder product. The NASA AIRS and NOAA IASI products are already defined to be on these levels, so the CrIMSS and GPS RO products are the only profiles that need to be interpolated. After the differences of the sounder minus GPS RO profiles are computed, they are degraded to approximate $1 \mathrm{~km}$ layer averages, as is done to the sounder minus reference differences in Susskind et al. (2003), Tobin et al. (2006), and Divakarla et al. (2006, 2014). Next, bias and root-mean-square (rms) profile statistics are calculated for various time and spatial scales. The spatial regions chosen for this study are global and five latitude zones that each span $30^{\circ}$ latitude, except for the tropical zone which spans $60^{\circ}$ latitude $\left(30^{\circ} \mathrm{N}-30^{\circ} \mathrm{S}\right)$. The bias and rms statistics are computed for the total number of samples within each zone without area weighting. Details of the sensitivity of this method to changes in the matchup criteria can be found in Feltz et al. (2014).

It should be noted that this comparison methodology does not address the error contributions due to the different vertical resolutions of the GPS RO and sounder profiles in an exact profile-by-profile method. Because averaging kernels, which represent the amount of information included in (or vertical resolution of) the sounder temperature retrievals, vary from retrieval to retrieval there is a contribution of error from treating all retrievals the same in regards to their vertical resolution. Rodgers and Connors (2003) demonstrate the exact, comprehensive method for comparing remote sounding instrument retrievals using averaging kernels. In current practice, however, the validation requirements of sounder products have been defined on layers of specified heights, and the creation of validation statistics has not involved the application of averaging kernels, but the averaging of the retrieval-minus-truth differences into vertical slab layers that the requirements are defined on (Susskind et al., 2011; Tobin et al., 2006; Divakarla et al., 2006, 2014). Thus, though this study does not make use of averaging kernels to account for the different vertical resolutions of the GPS RO and sounder profiles, it follows the previously and currently used practice of degrading the retrieval-minus-truth differences into $\sim 1 \mathrm{~km}$ layers. Table 1 illustrates the approximate vertical smoothing of the applied degradation in each latitude zone for the May 2012 COSMIC/AIRS matchup case. For each pressure level of the degraded zonal differences, the corresponding average COSMIC mean sea level height and top-bounding vertical slab layer width is shown. The vertical layers range from $\sim 0.75$ to $2.8 \mathrm{~km}$ with an average of $1.5 \mathrm{~km}$ between the vertical range of $1-300 \mathrm{hPa}$. The issue of vertical averaging is investigated further in Sect. 4.1.1 in a case study analysis.

In general, a comparison of independent measurements includes contributions from the uncertainty inherent in each
Table 2. Number of COSMIC matchups with AIRS, CrIMSS, and NOAA IASI for May 2012 selected latitude zones where quality controlled data were available.

\begin{tabular}{lrrr}
\hline \multicolumn{4}{c}{ Number of matchups with COSMIC } \\
\hline & AIRS & CrIMSS & NOAA IASI \\
\cline { 2 - 4 } Global & 6307 & 7532 & 7146 \\
$90-60^{\circ} \mathrm{N}$ & 1279 & 1767 & 2653 \\
$60-30^{\circ} \mathrm{N}$ & 1524 & 1659 & 1619 \\
$30^{\circ} \mathrm{N}-30^{\circ} \mathrm{S}$ & 1466 & 1597 & 629 \\
$30-60^{\circ} \mathrm{S}$ & 1331 & 1450 & 983 \\
$60-90^{\circ} \mathrm{S}$ & 707 & 1059 & 1262 \\
\hline
\end{tabular}

sensor product, as well as a sampling error of the time and space domain. The method described in Feltz et al. (2014) has the distinct advantage of minimizing sampling error by performing the comparison of individual GPS RO profiles matched in both time and space with IR/MW sounding retrievals. Comparisons can then be made at larger spatial and time scales knowing sampling error has been minimized in the comparison. It should be noted, however, that though the matchups are found within a strict 1-hour time difference, the distribution of matchups for a given GPS RO and sounder satellite comparison will be distinct in space and time due to the unique orbits of the polar orbiting satellites. The AIRS and CrIS sensors operate in the same orbit but are not time coincident, while the IASI sensor on the Metop platform is in a different orbit with few coincident matchups with AIRS and CrIS.

\section{Results}

In this study, bias and rms statistics are compared to illustrate (1) changes in sounder product performance due to processing version upgrades, (2) a comparison of operational sounding products from different satellite platforms, and (3) the consistency of GPS RO products from different sensor networks and instruments. A single month, May 2012, was chosen because data were available for all three sounder comparisons. Figure 1 shows the distributions of COSMIC dry temperature at two selected pressure levels, 11 and $77 \mathrm{hPa}$, for each of the global and five latitude zones for the COSMIC and AIRS matchup set. Note in the stratosphere at $11 \mathrm{hPa}$ during the month of May that the Northern Hemisphere and tropics are nearly the same temperature, much colder temperatures exist in the Southern Hemisphere, and this pressure level's temperatures reach a minimum in the Antarctic. For the tropical zone in Fig. 1, the $77 \mathrm{hPa}$ level highlights the extremely cold temperatures at the tropical tropopause. 

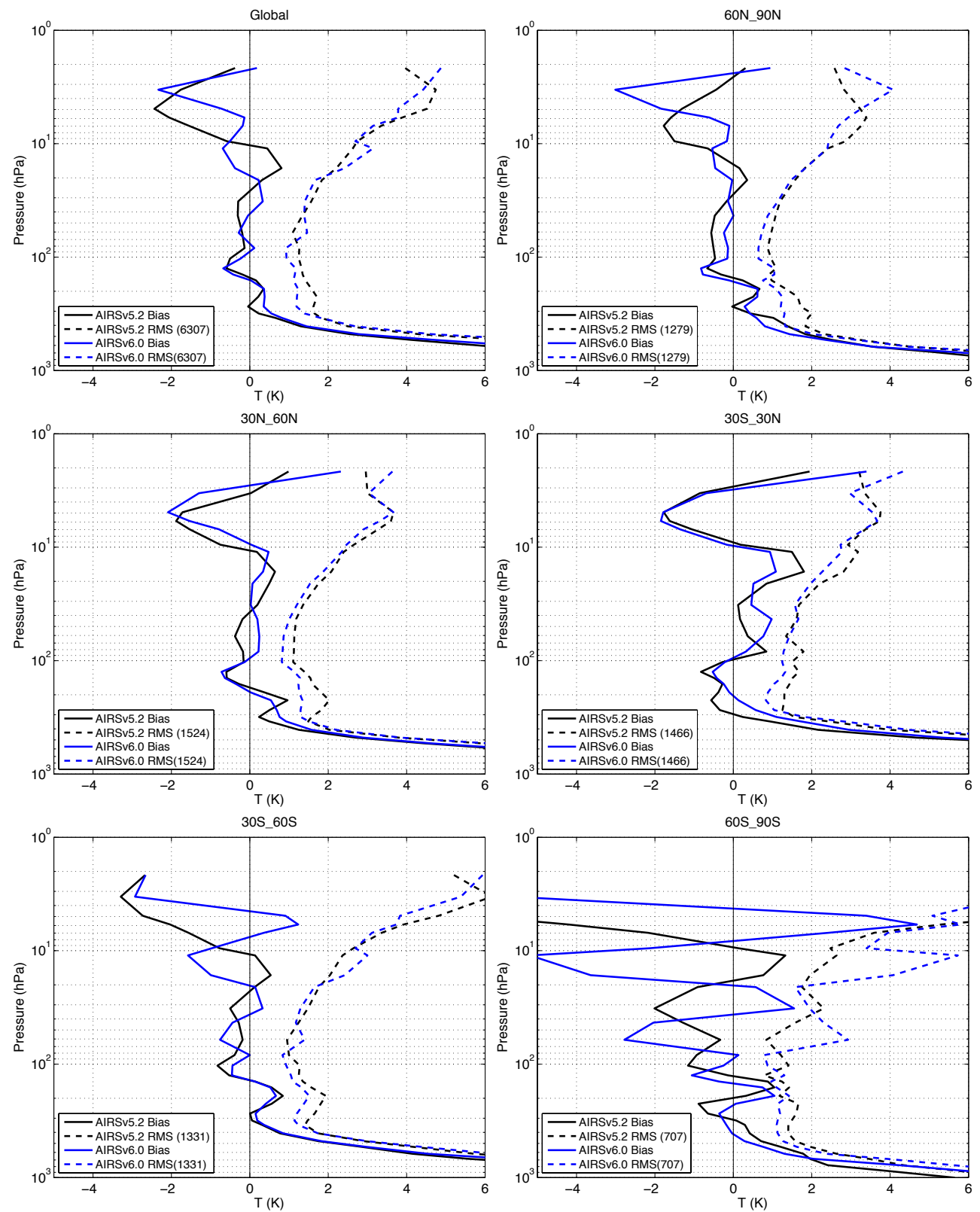

Figure 2. May 2012 NASA AIRS v5.2 minus COSMIC (black) and NASA AIRS v6.0 minus COSMIC (blue) bias (solid line) and rms (dashed line) for global and selected latitude zones. The apparent large positive biases in the middle and lower troposphere are due to the comparison with the COSMIC dry temperatures, which are significantly lower than actual temperatures when significant amounts of water vapor are present.

\subsection{Assessment of sounder product version update}

By using COSMIC dry temperature as the GPS RO reference, a comparison of sounder retrieval product version is presented in this section. Figure 2 compares the AIRS v5.2 and v6.0 statistics for the month of May 2012. The exact same COSMIC profiles are used in the two matchup sets, which allows evaluation of the changes due to the AIRS product algorithm. The number of matchup cases for COSMIC and AIRS is shown in the first column of Table 2. Feltz et al. (2014) conclude that the difference statistics become stable for a number of matchup cases greater than 200. Biases of AIRS v5.2 and v6.0 compared to COSMIC dry temperatures are generally less than $1 \mathrm{~K}$ between 10 and $300 \mathrm{hPa}$. Warm biases above $10 \mathrm{hPa}$ of up to $2 \mathrm{~K}$ exist. The apparent large warm biases below about $300 \mathrm{hPa}$ are due to the COSMIC dry temperatures being significantly lower than the actual temperatures due to the neglect of water vapor. 
Improvements in the AIRS global rms error of about $0.2 \mathrm{~K}$ are seen in the vertical range of 300 to $70 \mathrm{hPa}$ across most latitude zones when the GPS RO COSMIC profiles are used as a reference. In general, there is little improvement seen in the global bias. Larger differences between the versions in bias are seen in the Antarctic zone $\left(60-90^{\circ} \mathrm{S}\right)$ where vertical oscillations are apparent in the differences with respect to COSMIC.

\subsubsection{Antarctic averaging kernel application case study}

In order to more fully investigate the effect of the GPS RO and sounder vertical resolutions on the matchup statistics for the May 2012 Antarctic zone in Fig. 2, a comparison of vertical averaging methods is performed - specifically that of the slab layer degradation (as defined in Table 1) and application of a temperature averaging kernel. For this analysis, an AIRS averaging kernel (AK) is computed using the optimal spectral sampling radiative transfer model corresponding to the mean Antarctic zone ERA-Interim (ERA) state (Moncet et al., 2008). This approach is consistent with the Rodgers and Conners (2003) paper, which suggests computing the averaging kernel for the mean of the comparison data set.

Figure 3 shows the following comparisons done on the AIRS 101 pressure levels: AIRS minus COSMIC, AIRS minus $\mathrm{AK}^{*} \mathrm{COSMIC}$, and $\mathrm{AK} * \mathrm{AIRS}$ minus $\mathrm{AK} * \mathrm{COSMIC}$ plotted in panels from top to bottom. The notation $\mathrm{AK}^{*}$ denotes the application of the averaging kernel matrix, so respectively the first comparison shows non-vertically averaged results, the second shows the AK application to COSMIC profiles only, and the third shows the AK application to both COSMIC and AIRS profiles. The top and middle panels of Fig. 3 suggest that the oscillations present in the Antarctic zone bias shown in Fig. 2 are being introduced by the AIRS product and are not caused by the higher vertical resolution of the GPS RO. It is hypothesized that the original vertical oscillations prior to smoothing are likely due to the null space error for the Antarctic conditions, as application of the AK to the AIRS products greatly reduces the vertical oscillations in the original 101 level comparisons.

Figure 4 shows the mean ERA, COSMIC, AIRSv6, AK*COSMIC, and AK*AIRSv6 temperatures for Antarctic May 2012, as well as their departures from the mean ERA state. This further exemplifies that the oscillations of the AIRS minus COSMIC bias are an artifact of the AIRS retrievals. In fact, the vertical oscillations of the Antarctic zone bias are arguably larger in magnitude and more frequent in AIRS v6.0 than in AIRS v5.2, suggesting that the problem with AIRS v5.2 was not addressed in v6.0. It is outside the scope of this paper to explore the cause of this vertical oscillation in the AIRS product; however, the fact that the bias changes between version 5.2 and version 6.0 should be a clue to the root cause. The use of GPS RO data may be helpful in the resolution of this issue.
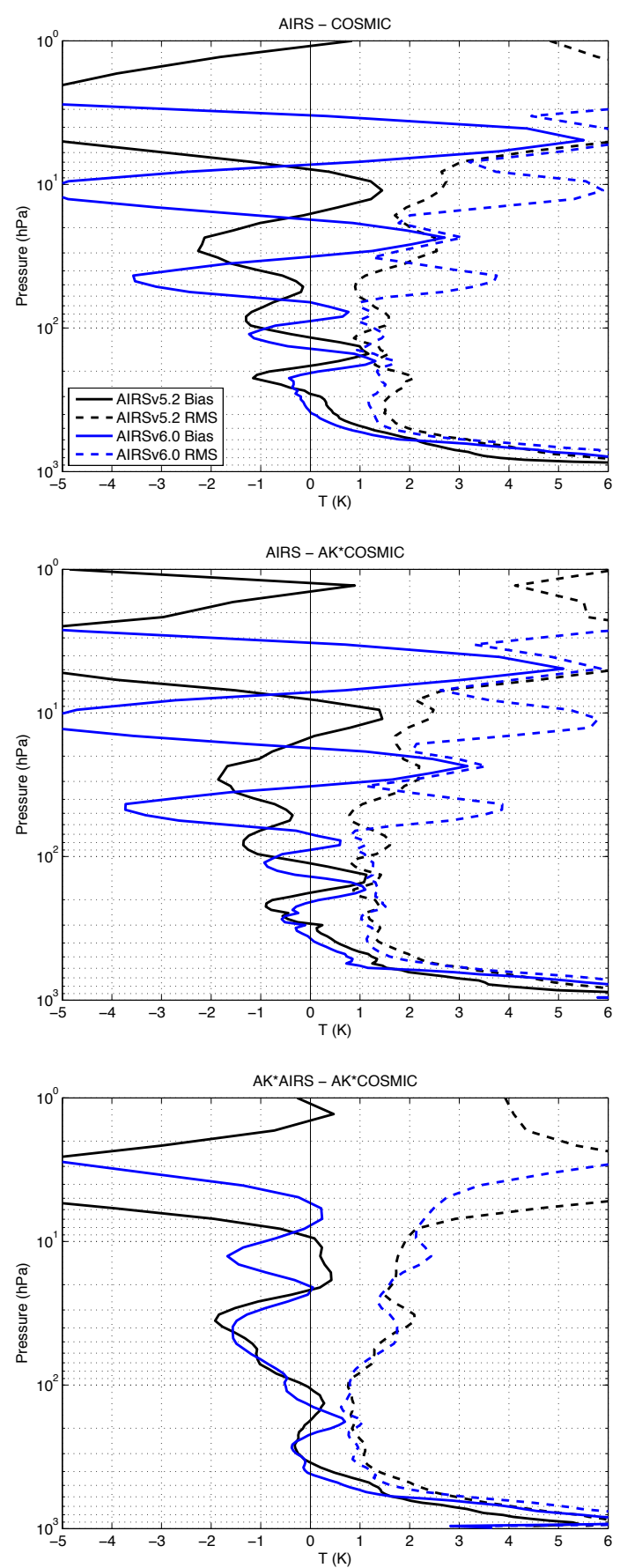

Figure 3. Antarctic May 2012 AIRS v5.2 minus COSMIC (black) and AIRS v6.0 minus COSMIC (blue) bias (solid) and rms (dashed) for the following three cases: (top) no averaging kernel application, (middle) AIRS averaging kernel application to COSMIC profiles, and (bottom) AIRS averaging application to both COSMIC and AIRS profiles. The apparent large positive biases in the middle and lower troposphere are due to the comparison with the COSMIC dry temperatures, which are significantly lower than actual temperatures when significant amounts of water vapor are present. 
Table 3. Number of COSMIC and GRAS profiles and matchup cases with IASI for May 2012 selected latitude zones.

\begin{tabular}{lrr}
\hline & COSMIC & GRAS \\
\hline & \multicolumn{2}{c}{ IASI matchup cases } \\
\cline { 2 - 3 } Global & 7146 & 7303 \\
$90-60^{\circ} \mathrm{N}$ & 2653 & 1191 \\
$60-30^{\circ} \mathrm{N}$ & 1619 & 1577 \\
$30^{\circ} \mathrm{N}-30^{\circ} \mathrm{S}$ & 629 & 1574 \\
$30-60^{\circ} \mathrm{S}$ & 983 & 1685 \\
$60-90^{\circ} \mathrm{S}$ & 1262 & 1276 \\
\hline & \multicolumn{2}{c}{ Total profiles } \\
\cline { 2 - 3 } Global & 29671 & 16104 \\
$90-60^{\circ} \mathrm{N}$ & 3992 & 2223 \\
$60-30^{\circ} \mathrm{N}$ & 7923 & 3245 \\
$30^{\circ} \mathrm{N}-30^{\circ} \mathrm{S}$ & 9338 & 4936 \\
$30-60^{\circ} \mathrm{S}$ & 6148 & 3440 \\
$60-90^{\circ} \mathrm{S}$ & 2270 & 2260 \\
\hline
\end{tabular}

\subsection{Sounder product comparison}

Figure 5 compares three different sounder temperature retrieval products - AIRS v5.2, NOAA IASI, and CrIMSS Mx5.3 - using COSMIC as the reference GPS RO source. Statistics of the three sounder minus COSMIC profile sets for the month of May 2012 are overlaid. The number of matchup cases for all three matchup sets are shown in Table 2. For the May 2012 time period, the CrIMSS product is the beta release, whereas the NASA AIRS and NOAA IASI are products that have had many years of development. NASA AIRS v5.2 and NOAA IASI are nearly the same algorithm applied to the different sensors, so it is not surprising that they share many common characteristics. In contrast, the CrIMSS algorithm is an entirely new algorithm with relatively little heritage; therefore it benefits from comparison to the heritage AIRS and NOAA IASI algorithms. This example illustrates the value of having a common GPS RO reference so that products derived from any sounder satellite can be objectively compared and the differences quantified.

While the global statistics in Fig. 5 show a somewhat similar bias pattern among the three sounder cases, zonal statistics such as the Antarctic zone $\left(60-90^{\circ} \mathrm{S}\right)$ show a wider variance between the sounder minus GPS RO bias patterns. In particular, the CrIMSS product does not have the same vertical oscillations seen in the AIRS and NOAA IASI products, which may be a clue to the source of a retrieval artifact.

\subsection{GPS RO product comparison}

In this section, two GPS RO products are compared to a similar sounder reference in an attempt to evaluate the differences between the GPS RO products. The motivations for the following comparison are to determine whether the presented
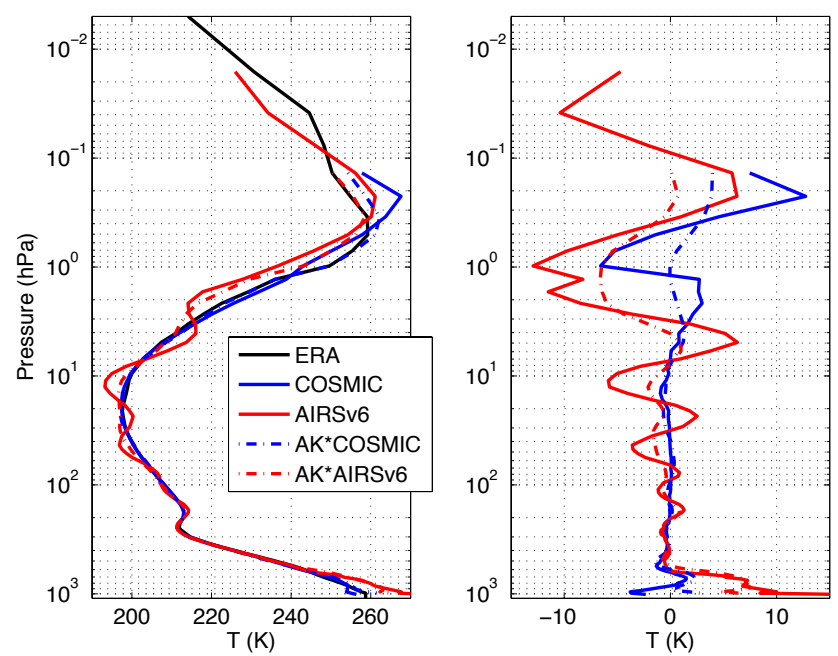

Figure 4. Antarctic May 2012 COSMIC/AIRS matchup mean ERA (black), COSMIC (blue solid), AIRS (red solid), AK*COSMIC (dashed blue), and AK*AIRS (red dashed) temperatures (left) and departures of these means from the ERA mean (right). AK* denotes application of the averaging kernel.

methodology can actually detect the differences between two GPS RO products as well as attempt to quantify the error in using either GPS RO product as a reference for sounder evaluation. Specifically, NOAA IASI is used to compare the UCAR dry temperature products derived from the COSMIC and GRAS sensors. The differences in the UCAR data processing between COSMIC and GRAS are briefly discussed in Sect. 2.1.

The numbers of matchup cases for this comparison are shown in top panel of Table 3 by latitude zone. Though the number of matchups for COSMIC/NOAA IASI is less than half that of GRAS/NOAA IASI in the tropics $\left(30^{\circ} \mathrm{N}-30^{\circ} \mathrm{S}\right)$, this region is known to have less variability than others. The total number of profiles of the COSMIC network and MetopA GRAS instrument is noted in the bottom panel of Table 3. Though GRAS roughly has less than half the total number of profiles than COSMIC in most latitude zones, GRAS typically has a comparable (or greater) number of matchup cases to COSMIC, as GRAS and IASI are located on the same platform.

Figure 6 shows the difference of IASI minus COSMIC and IASI minus GRAS statistics, which is the equivalence of a GRAS minus COSMIC comparison, for May 2012. Overlaid with this result is the difference of the mean COSMIC temperature (calculated by using all of the profiles, not just the restricted matchup set profiles) from the mean GRAS temperature for each latitude zone (dashed line). The global mean temperatures for the complete COSMIC and GRAS data sets are area-weighted averages which use the cosine of latitude applied to $1^{\circ}$ latitude bins. The two overlaid results are in qualitative agreement in the vertical range of 500$3 \mathrm{hPa}$ in most latitude zones, except for the Antarctic zone. 

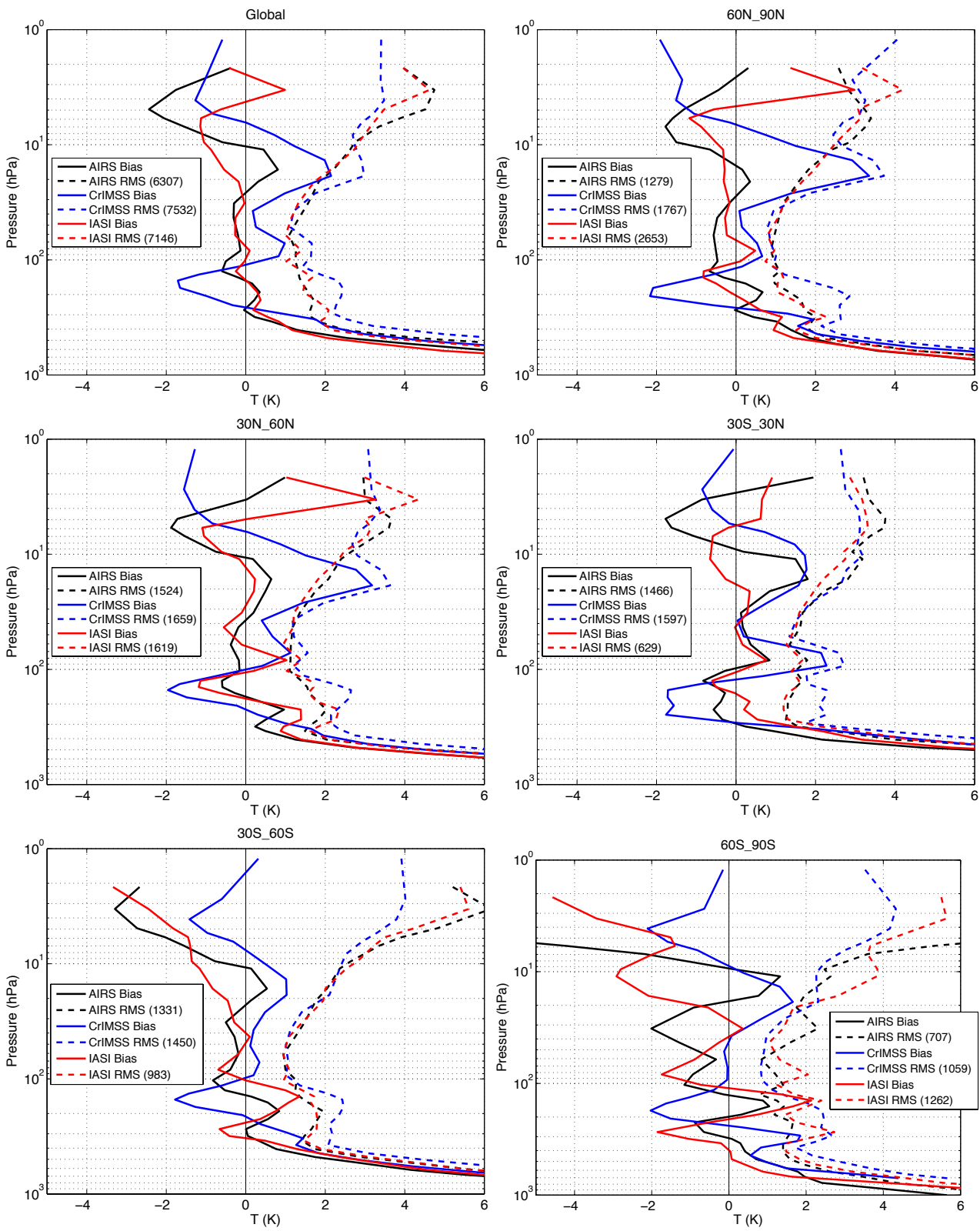

Figure 5. Bias (solid) and rms (dashed) error profiles from three operational sounder platforms (Aqua, Suomi NPP, and Metop-A) for May 2012 using COSMIC as a common reference. The three operational products shown are NASA AIRS v5.2 (black), NOAA IASI (red), and JPSS CrIMSS Mx5.3 (blue) for global and five latitude zones. The apparent large positive biases in the middle and lower troposphere are due to the comparison with the COSMIC dry temperatures, which are significantly lower than actual temperatures when significant amounts of water vapor are present.

In the Antarctic zone, the apparent shift of the dashed curve from the IASI results indicates a difference in mean temperature between GRAS and COSMIC for May 2012; however, the vertical shapes of the biases are quite consistent. Above the $100 \mathrm{hPa}$ level, the GRAS minus COSMIC biases grow with altitude throughout the stratosphere but with different signs for the two hemispheres. Since the hemispheric biases nearly cancel, the global bias is much smaller and would not indicate the problem that is illustrated in the zonal analysis.

\section{Conclusions}

The GPS RO dry temperature is shown to be useful for the evaluation of MW/IR sounder retrieved temperature profiles in the 300 to $10 \mathrm{hPa}$ region on monthly timescales and zonal to global spatial scales. The absolute accuracy of the GPS RO COSMIC data is used to show a small temperature improvement in the AIRS v6.0 product over the previous v5.2. The GPS RO network can be used as a common reference 

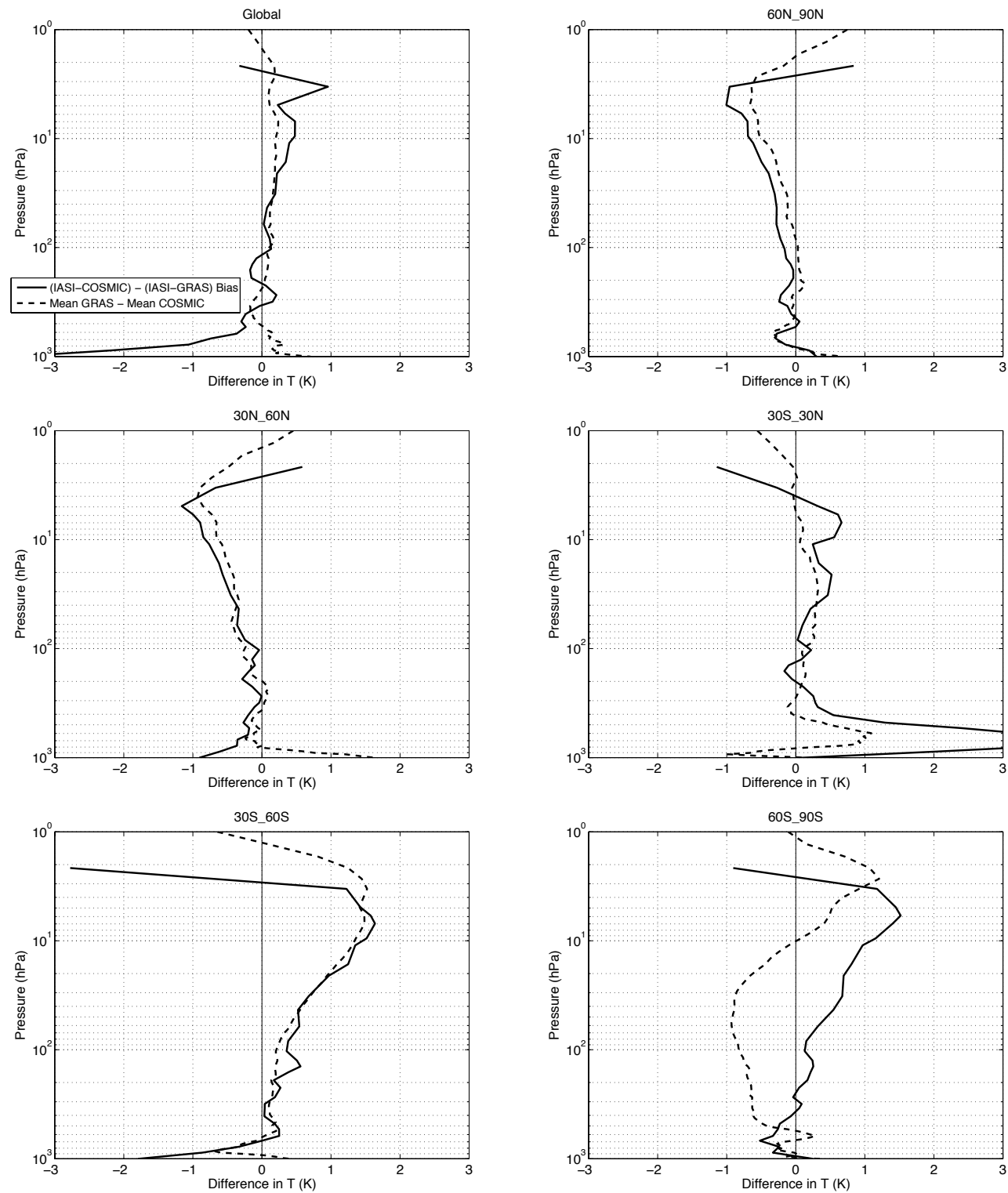

Figure 6. May 2012 (NOAA IASI minus COSMIC) minus (NOAA IASI minus GRAS) bias (solid) and mean GRAS minus mean COSMIC (dashed) for global and selected latitude zones.

for the comparison of sounder products from different sensors on different satellite platforms using different retrieval algorithms. The sounder minus GPS RO statistics have characteristic structures on zonal scales.

In particular, the Antarctic zone tends to have the greatest sounder errors for the time period studied, May 2012. The results indicate the need for further detailed analysis of vertical resolution issues in GPS RO and sounder comparisons. These facts support the conclusion that zonal analysis and validation needs to be done for the sounder profile products, as global comparisons will hide compensating local biases.

A limited study of the consistency between COSMIC and GRAS dry temperature products, both produced using
UCAR processing, was performed on zonal scales. A hemispheric bias was seen between COSMIC and GRAS products, which nearly cancels in the global mean. Further investigation of possible GRAS and COSMIC systematic biases is justified by these results.

Future work will be directed toward regional analyses, an application of the comparison method to other current operational GPS RO and sounder data sets, an extension of the comparisons to additional time periods, and a comparison of the complete AIRS L2 temperature version 5 and 6 records using GPS RO data to assess the climate quality of the sounder data. 
Acknowledgements. We acknowledge and thank the NPSO (Taiwan's National Space Organization) and UCAR (University Corporation for Atmospheric Research) for access to the GPS RO data used in this study. The AIRS level 2 data products were accessed through the Goddard Space Flight Center (GSFC) Data Archive. This work was supported under JPSS NOAA grant NA10NES4400013.

Edited by: R. Anthes

\section{References}

Anthes, R. A., Bernhardt, P. A., Chen, Y., Cucurull, L., Dymond, K. F., Ector, D., Healy, S. B., Ho, S.-P., Hunt, D. C., Kuo, Y.-H., Liu, H., Manning, K., McCormick, C., Meehan, T. K., Randel, W. J., Rocken, C., Schreiner, W. S., Sokolovskiy, S. V., Syndergaard, S., Thompson, D. C., Trenberth, K. E., Wee, T.-K., Yen, N. L., and Zeng, Z.: The COSMIC/FORMOSAT-3 mission: Early results, B. Am. Meteorol. Soc., 89, 313-333, 2008.

Divakarla, M., Barnet, C., Goldberg, M., McMillin, L., Maddy, E., Wolf, W., Zhou, L., and Liu, X.: Validation of Atmospheric Infrared Sounder temperature and water vapor retrievals with matched radiosonde measurements and forecasts, J. Geophys. Res.-Atmos., 111, 1984-2012, doi:10.1029/2005JD006116, 2006.

Divakarla, M., Barnet, C., Liu, X., Gu, D., Wilson, M., Kizer, S., Xiong, X., Maddy, E., Ferraro, R., Knuteson, R., Hagan, D., Ma, X.-L., Tan, C., Nalli, N., Reale, A., Mollner, A. K., Yang, W., Gambacorta, A., Feltz, M., Iturbide-Sanchez, F., Sun, B., and Goldberg, M.: The CrIMSS EDR algorithm: Characterization, optimization, and validation, J. Geophys. Res.-Atmos., 119, 4953-4977, doi:10.1002/2013JD020438, 2014.

Feltz, M. L., Knuteson, R. O., Revercomb, H. E., and Tobin, D. C.: A methodology for the validation of temperature profiles from hyperspectral infrared sounders using GPS radio occultation: Experience with AIRS and COSMIC, J. Geophys. Res.-Atmos.,119, 1680-1691, doi:10.1002/2013JD020853, 2014.

Fetzer, E., McMillin, L. M., Tobin, D., Aumann, H. H., Gunson, M. R., McMillan, W. W., Hagan, D. E., Hofstadter, M. D., Yoe, J., Whiteman, D. N., Barnes, J. E., Bennartz, R., Vömel, H., Walden, V., Newchurch, M., Minnett, P. J., Atlas, R., Schmidlin, F., Olsen, E. T., Goldberg, M. D., Zhou, S., Ding, H., Smith, W. L., and Revercomb, H.: AIRS/AMSU/HSB validation, IEEE T. Geosci. Remote, 41, 418-431, 2003.

Foelsche, U., Borsche, M., Steiner, A., Gobiet, A., Pirscher, B., Kirchengast, G., Wickert, J., and Schmidt, T.: Observing upper troposphere-lower stratosphere climate with radio occultation data from the CHAMP satellite, Clim. Dynam., 31, 49-65, doi:10.1007/s00382-007-0337-7, 2008.

Hajj, G., Kursinski, E., Romans, L., Bertiger, W., and Leroy, S.: A technical description of atmospheric sounding by GPS occultation, J. Atmos. Sol.-Terr. Phy., 64, 451-469, doi:10.1016/S13646826(01)00114-6, 2002.

Ho, S.-P., Goldberg, M., Kuo, Y.-H., Zou, C.-Z., and Schreiner, W.: Calibration of temperature in the lower stratosphere from microwave measurements using COSMIC radio occultation data: Preliminary results, Terr., Atmos. Ocean. Sci., 20, 87-100, doi:10.3319/TAO.2007.12.06.01(F3C), 2009.
Ho, S.-P., Hunt, D., Steiner, A. K., Mannucci, A. J., Kirchengast, G., Gleisner, H., Heise, S., von Engeln, A., Marquardt, C., Sokolovskiy, S., Schreiner, W., Scherllin-Pirscher, B., Ao, C., Wickert, J., Syndergaard, S., Lauritsen, K. B., Leroy, S., Kursinski, E. R., Kuo, Y.-H., Foelsche, U., Schmidt, T., and Gorbunov, M.: Reproducibility of GPS radio occultation data for climate monitoring: Profile-to-profile inter-comparison of CHAMP climate records 2002 to 2008 from six data centers, J. Geophys. Res., 117, D18111, doi:10.1029/2012JD017665, 2012.

JPSS Configuration Management Office: Joint Polar Satellite System (JPSS) Algorithm Theoretical Basis Document For the Cross Track Infrared Sounder (CrIS) Volume II, Environmental Data Records (EDR), JPSS office, document code 474: 474-00056, available at: http://npp.gsfc.nasa.gov/documents.html (last access: 04 June 2014), 2012

Klaes, K. D., Cohen, M., Buhler, Y., Schlüssel, P., Munro, R., Luntama, J.-P., von Engeln, A., O'Clerigh, E., Bonekamp, H., Ackermann, J., and Schmetz, J.: An introduction to the EUMETSAT polar system, B. Am. Meteorol. Soc., 88, 1085-1096, doi:10.1175/BAMS-88-7-1085, 2007.

Kursinski, E. R., Hajj, G., Schofield, J., Linfield, R., and Hardy, K.: Observing Earth's atmosphere with radio occultation measurements using the Global Positioning System, J. Geophys. Res., 102, 23429-23465, 1997.

Leroy, S. S., Dykema, J. A., and Anderson, J. G.: Climate benchmarking using GNSS occultation, Atmosphere and Climate, Springer, Berlin Heidelberg, 287-301, 2006.

Mannucci, A. J., Ao, C. O., Yunck, T. P., Young, L. E., Hajj, G. A., Iijima, B. A., Kuang, D., Meehan, T. K., and Leroy, S. S.: Generating climate benchmark atmospheric soundings using GPS occultation data, Proc. SPIE 6301, P. Soc. Photo.-Opt. Ins., 630108, doi:10.1117/12.683973, 2006.

McNally, A. P., Watts, P. D., Smith, J. A., Engelen, R., Kelly, G. A., Thépaut, J. N., and Matricardi, M.: The assimilation of AIRS radiance data at ECMWF, Q. J. Roy. Meteor. Soc., 132, 935-957, doi:10.1256/qj.04.171, 2006.

Moncet, J-L., Uymin, G., Lipton, A. E., and Snell, H. E.: Infrared radiance modeling by Optimal Spectral Sampling, J. Atmos. Sci., 65, 3917-3934, doi:10.1175/2008JAS2711.1, 2008.

Nalli, N. R., Barnet, C. D., Reale, A., Tobin, D., Gambacorta, A., Maddy, E. S., Joseph, E., Sun, B., Borg, L., Mollner, A. K., Morris, V. R., Liu, X., Divakarla, M., Minnett, P. J., Knuteson, R. O., King, T. S., and Wolf, W. W.: Validation of satellite sounder environmental data records: Application to the Cross-track Infrared Microwave Sounder Suite, J. Geophys. Res.-Atmos., 118, 13628-13643, doi:10.1002/2013JD020436, 2013.

Reale, T., Sun, B., Tilley, F. H., and Pettey, M.: The NOAA Products Validation System, J. Atmos. Ocean. Tech., 29, 629-645, doi:10.1175/JTECH-D-11-00072.1, 2012.

Rodgers, C. D. and Connor, B. J.: Intercomparison of remote sounding instruments, J. Geophys. Res., 108, 4116, doi:10.1029/2002JD002299, 2003.

Seidel, D. J., Berger, F. H., Diamond, H. J., Dykema, J., Goodrich, D., Immler, F., Murray, W., Peterson, T., Sisterson, D., Sommer, M., Thorne, P., Vömel, H., and Wang, J.: Reference upper-air observations for climate: Rationale, progress, and plans, B. Am. Meteorol. Soc., 90, 361-369, 2009.

Seidel, D. J., Gillett, N. P., Lanzante, J. R., Shine, K. P., and Thorne, P. W.: Stratospheric temperature trends: Our 
evolving understanding, WIREs, Clim. Change, 2, 592-616, doi:10.1002/wcc.125, 2011.

Staten, P. W. and Reichler, T.: Apparent precision of GPS radio occultation temperatures, Geophys. Res. Lett., 36, L24806, doi:10.1029/2009GL041046, 2009.

Steiner, A. K., Lackner, B. C., Ladstädter, F., Scherllin-Pirscher, B., Foelsche, U., and Kirchengast, G.: GPS radio occultation for climate monitoring and change detection, Radio Sci., 46, RSOD24, doi:10.1029/2010RS004614, 2011.

Steiner, A. K., Hunt, D., Ho, S.-P., Kirchengast, G., Mannucci, A. J., Scherllin-Pirscher, B., Gleisner, H., von Engeln, A., Schmidt, T., Ao, C., Leroy, S. S., Kursinski, E. R., Foelsche, U., Gorbunov, M., Heise, S., Kuo, Y.-H., Lauritsen, K. B., Marquardt, C., Rocken, C., Schreiner, W., Sokolovskiy, S., Syndergaard, S., and Wickert, J.: Quantification of structural uncertainty in climate data records from GPS radio occultation, Atmos. Chem. Phys., 13, 1469-1484, doi:10.5194/acp-13-1469-2013, 2013.

Susskind, J., Barnet, C., Blaisdell, J., Iredell, L., Keita, F., Kouvaris, L., Molnar, G., and Chahine, M.: Accuracy of geophysical parameters derived from Atmospheric Infrared Sounder/Advanced Microwave Sounding Unit as a function of fractional cloud cover, J. Geophys. Res., 111, D09S17, doi:10.1029/2005JD006272, 2006.

Susskind, J., Blaisdell, J. M., Iredell, L., and Keita, F.: Improved temperature sounding and quality control methodology using AIRS/AMSU data: The AIRS Science Team Version 5 retrieval algorithm, IEEE T. Geosci. Remote, 49, 883-907, 2011.

Thompson, A. and Taylor, B. N.: Guide for the Use of the International System of Units (SI), National Institute of Standards and Technology, 2008.

Thorne, P. W., Lanzante, J. R., Peterson, T. C., Seidel, D. J., and Shine, K. P.: Tropospheric temperature trends: History of an ongoing controversy, WIREs, Clim. Change, 2, 66-88, doi:10.1002/wcc.80, 2011.
Tobin, D. C., Revercomb, H. E., Knuteson, R. O., Lesht, B. M., Strow, L. L., Hannon, S. E., Feltz, W. F., Moy, L. A., Fetzer, E. J., and Cress, T. S.: Atmospheric Radiation Measurement site atmospheric state best estimates for Atmospheric Infrared Sounder temperature and water vapor retrieval validation, J. Geophys. Res., 111, D09S14, doi:10.1029/2005JD006103, 2006.

Turner, D. D., Lesht, B. M., Clough, S. A., Liljegren, J. C., Revercomb, H. E., and Tobin, D. C.: Dry Bias and Variability in Vaisala RS80-H Radiosondes: The ARM Experience, J. Atmos. Ocean. Technol., 20, 117-132, 2003.

von Engeln, A., Accadia, C., Ackermann, J., Marquardt, C., Andres, Y., Lazaro, D., and Klaes, K. D.: Potentials for radio occultation applications during inter-satellite calibration periods, Adv. Space Res., 47, 1731-1742, doi:10.1016/j.asr.2010.05.001, 2010.

Ware, R., Exner, M., Feng, D., Gorbunov, M., Hardy, K., Herman, B., Kuo, Y., Meehan, T., Melbourne, W., Rocken, C., Schreiner, W., Sokolovskiy, S., Solheim, F., Zou, X., Anthes, R., Businger, S., and Trenberth, K.: GPS Sounding of the atmosphere from low earth orbit: Preliminary results, B. Am. Meteorol. Soc., 77, 19-40, doi:10.1175/15200477(1996)077<0019:GSOTAF>2.0.CO;2, 1996.

Weng, F., Zou, X., Sun, N., Yang, H., Tian, M., Blackwell, W. J., Wang, X., Lin, L., and Anderson, K.: Calibration of Suomi national polar-orbiting partnership advanced technology microwave sounder, J. Geophys. Res.-Atmos., 118, 11187-11200, doi:10.1002/jgrd.50840, 2013.

Yunck, T. P., Fetzer, E. J., Mannucci, A. M., Ao, C. O., Irion, W., Wilson, B. D., and Manipon, G. J.: Use of radio occultation to evaluate atmospheric temperature data from spaceborne infrared sensors, Terr. Atmos. Ocean. Sci., 20, 71-85, 2009.

Zou, X., Lin, L., and Weng, F.: Absolute calibration of ATMS upper level temperature sounding channels using GPS RO observations, IEEE T. Geosci. Remote, 52, 1397-1406, doi:10.1109/TGRS.2013.2250981, 2014. 